\title{
Do interactions cancel associations of subjective well-being with individual-level socioeconomic characteristics? An exploratory analysis using the European Social Survey
}

\author{
Takis Venetoklis ${ }^{1}$ \\ Published online: 31 July 2019 \\ (c) The Author(s) 2019
}

\begin{abstract}
Using the European Social Survey (2002-2014, 16 countries, N=146,579), I examine whether significant associations between self-reported subjective well-being (SWB) and thirteen individual-level socioeconomic characteristics still hold in specific population sub-groups. The determinants are age, gender, children at home, education, work status, religiosity, political orientation, trust towards the parliament and the legal system, meeting friends, marital status, health and finances. Based on each characteristic's values, I divide the sample into sub-groups and run separate regressions. Compared to regressions using the whole sample, only six of the aforementioned characteristics maintain the same association with SWB. For age, gender, children at home, education, religiosity and trust the previous associations with SWB now disappear. These results contradict prior theoretical and empirical findings.
\end{abstract}

Keywords Subjective well-being $\cdot$ Socioeconomic characteristics $\cdot$ Happiness $\cdot$ European Social Survey $\cdot$ Exploratory research $\cdot$ Interactions

\section{Introduction}

Since the 1950s, subjective well-being $(\mathrm{SWB})^{1}$ has become a very popular research field in many disciplines including Psychology, Economics, and Sociology. A considerable amount of relevant research had already been conducted by the early 1980s, as discussed in the seminal paper of the pioneering Diener (1984). In recent years, a plethora of reviews and meta-analyses have focused on the topic (e.g. Dolan et al. 2008, Eger and Maridal 2015; Jorm and Ryan 2014; Lane 2017; Lyubomirsky et al. 2005).

\footnotetext{
1 In the paper, I use 'happiness', 'well-being', and 'SWB' interchangeably, which is common in literature. Likewise, I use 'characteristics', 'determinants', 'predictors', and 'factors' interchangeably. These refer to the independent variables of the regression models presented in the Sect. 3.

Takis Venetoklis

ta_vene@yahoo.com; panven@utu.fi

1 Department of Social Research/Social Policy, University of Turku, Assistentinkatu 7, Publicum 3rd Floor, 20014 Turun Yliopisto, Finland
} 
Why do researchers study SWB? As Diener and Ryan (2009, p. 392) argue, the main applied goal when studying SWB is improving people's lives 'beyond the elimination of misery'. Research shows that individuals scoring high on SWB are healthier, and live longer. They are also more successful regarding marriage, friendships, income levels, and working career (Lyubomirsky et al. 2005, p. 803). Beyond the individual level, this helps the smooth functioning of work organisations and, in turn, democratic systems. Put differently, high SWB at individual level can spill over and benefit overall society by making it function more effectively (Diener and Biswas-Diener 2008). Stiglitz et al. (2010) warn however that aggregate economic indicators should not be used to measure national wellbeing. For example, a country's GDP may give an overall picture of a nation's wealth and progress, but cannot effectively capture well-being at individual level. Instead, SWB helps us to better monitor social progress and relevant policies (Taylor 2011). Thus, by measuring SWB, we can roughly estimate people's quality of life and then, ideally, design and implement policies for improving it.

\subsection{Why study factors (characteristics) associated with SWB?}

A fundamental goal of any democratically elected government is to implement policies that maximise citizen well-being (Fleche et al. 2011, p. 5). Evaluation of such policies' goodness interests not only national governments but also international organisations. The Commission on the Measurement of Economic Performance and Social Progress (Stiglitz et al. 2009, 2010) recommended that, alongside economic data, subjective measures of well-being should be used to assess social progress and evaluate relevant policy. Similarly, the World Happiness Report 2016 (Helliwell et al. 2016) highlighted that SWB measurements can be used to effectively assess a nation's progress. In fact, several economists even propose SWB as a substitute for utility, a central notion in economic theory (Helliwell and Barrington-Leigh 2010). I would, thus, argue that motivations for studying SWB include both pure academic interest and the policy implications of research findings. As Ngamada (2017, p. 377) explains, to design and implement policies that would maximise SWB, it is first imperative to 'identify the most important factors that are associated with it'.

Economists, for example, have been investigating the factors that influence individuallevel happiness, and how lower SWB relates to unemployment (Ferrer-i-Carbonell 2013, p. 37). Unemployment can indeed be detrimental to individual SWB, with negative social and health repercussions, whereas a regular salary produces the opposite effect. (Cole et al. 2009; Diener and Chan 2011; Headey and Wearing 1990; Kilian et al. 2012; Tay and Diener 2011). Broyd et al. (2016, p. 429) report that maximising SWB produces, besides economic advantages, obvious benefits for special sub-groups of the population, such as people with severe mental illness. Lukaschek et al. (2017) investigated risk factors associated with low SWB in males and females aged 65 and over. Depression, anxiety, and sleeping problems seemed to be associated with low SWB in both sexes. They conclude that increased mental health interventions are required, especially among lone-dwelling females.

\subsection{Commonly studied factors of SWB}

For the last 40 years, examination of SWB factors has been the favourite topic of many psychologists. The 'Big Five' personality traits Extraversion, Agreeableness, Openness to experience, Conscientiousness, and Neuroticism (McCrae and Costa 1987, 1997; McCrae 
and Terracciano 2005) appear to be the strongest factors associated with SWB (Cheng and Furnham 2014). This connection has also been demonstrated by Headey and Wearing (1992), who assert that personality traits influence one's ability to adapt to changes and maintain happiness. This was also confirmed in DeNeve and Cooper's (1998) meta-analysis, in which three of the big five factors-neuroticism, extraversion, and agreeablenesswere reported to be strong predictors of life satisfaction and happiness. In other words, genes predispose a person to behave in a certain way and, thus, influence their well-being.

Social scientists have not generally had access to such personality characteristics of individuals, however. Instead, their empirical research on SWB has been primarily based on survey data. In addition to such generic components of SWB, other demographic and socioeconomic characteristics have been found to correlate with self-reported happiness levels. In their very comprehensive meta-analysis, Dolan et al. (2008, p. 97) classify seven potential 'influences' (variables) on well-being: (1) income-related; (2) personal characteristics (age, gender, ethnicity, personality); (3) socially developed characteristics (education, health, type of work, unemployment); (4) how we spend our time (hours worked, commuting, caring for others, community involvement and volunteering, exercise, religious activities); (5) attitudes and beliefs towards self/other/life (attitudes towards our circumstances, trust, political persuasion, religion); (6) relationships (marriage and intimate relationship, having children, seeing family and friends); and (7) the wider economic, social, and political environment (e.g. income inequality, unemployment rate, GDP, inflation level, welfare system and public insurance, degree of democracy, climate and natural environment, safety and deprivation of the area, urbanisation).

The latter category of aggregate-level macro-economic indicators that allegedly influence SWB is beyond this paper's scope. I concentrate on the first six groups, which are individual-level characteristics. The literature includes studies analysing individual-level data through recurring surveys of the general population, but using only some of the above predictors. This can be attributed to the unavailability of all relevant variables in the databases utilised. Notable exceptions are recent studies by Ngamaba (2017), who analysed responses of about 85,000 individuals from 59 countries using 21 variables (determinants) of SWB, Diego-Rossell et al. (2018), with 276,000 observations from 122 countries and 60 variables, and Jun (2015), with 175,000 observations from 59 countries and 19 variables.

\subsection{Goals and hypotheses}

I use data from the European Social Survey (ESS), a biennial survey conducted since 2002. The data include responses from individuals in 16 European countries for all seven survey rounds between 2002 and 2014. They were Belgium (BE), Switzerland (CH), Germany (DE), Denmark (DK), Estonia (ES), Finland (FI), France (FR), Great Britain (GB), Hungary (HU), Ireland (IE), Netherlands (NL), Norway (NO), Poland (PL), Portugal (PT), Sweden (SE), and Slovakia (SI). I selected these countries because they are the only ones (of 36 in total) to have participated in all seven ESS rounds. I examine whether individuallevel socioeconomic characteristics previously reported to be associated with SWB still have the same effect and show which have the strongest association. I then analyse whether these associations are changed when breaking the sample into smaller groups. I hypothesise that some of the previously reported associations will not persist after such division of the data. Hence, using the split data, the goal is to identify those characteristics whose relation with SWB is unaltered and those for which, contrary to prior findings, the association 
disappears. To this end, I compare the statistical significance of the coefficients of each characteristic between the model for the whole dataset and sub-group models.

In the following section, I briefly describe the data and the dependent and independent variables selected for statistical analysis. In Sect. 3, I explain the logic behind the regression models and comment on the results. In the same section, I refer to similar studies on the subject to compare my findings with theirs, focusing mostly on research after 1990. In the final section, I summarise and discuss my findings.

\section{Data}

\subsection{Dependent variable}

In psychology, SWB is a 'general assessment' of how one feels about one's life (Sumner 1996). Life satisfaction describes a cognitive judgement, whereas happiness refers to an emotional state. Happiness and life satisfaction are, thus, basic components of SWB. In the ESS, they are measured via the following Likert-scale questions:

Taking all things together, how happy would you say you are?

(0 - Extremely unhappy to 10 - Extremely happy)

All things considered, how satisfied are you with your life as a whole nowadays?

(0 - Extremely unsatisfied to 10 - Extremely satisfied)

In previous studies, the correlation between self-reported levels of happiness and life satisfaction has varied. For example, in WVS data for 1981-2005, it was only 0.47 (Eger and Maridal 2015, p. 46). In my dataset, the overall correlation of the two variables was 0.628 . Per country, it ranged from 0.393 to 0.672 , and per survey-round (year) from 0.600 to 0.650 . Following Eger and Maridal (2015), I use their mean value as the indicator of (self-reported) SWB.

\subsection{Independent variables}

The ESS includes responses for most of the individual-level variables listed in Introduction. However, not all were measured in all seven rounds. Also recall that not all countries participated in each round. Due to these limitations, and after considering each variable's relevant importance to SWB, I selected the following 13 individual-level socioeconomic characteristics: age, gender, children at home, educational level, (daily) activity/work status, religious activity, political orientation, trust towards the parliament and the legal system, frequency of meeting with friends, marital status, self-reported health status, and coping with finances. In the regression models, I also added the respondent's Country, the survey Round, and their interaction as control variables.

\subsection{Descriptives}

By only including responses from countries that participated in all seven ESS rounds from 2002 to 2014, the dataset was limited to 16 of the 36 countries included in one or more of the survey rounds. However, the benefit of such a restricted approach is a homogenous dataset with no missing values. We can, therefore, use both these variables and their 
Table 1 Descriptive statistics of variables utilized in models $(\mathrm{N}=146,579)$

\begin{tabular}{|c|c|c|c|c|}
\hline Variable & Mean & SD & Min & Max \\
\hline How happy are you? (0 to 10$)$ & 7.657 & 1.557 & 0.000 & 10.000 \\
\hline How satisfied are you with your life? (0 to 10 ) & 7.380 & 1.862 & 0.000 & 10.000 \\
\hline $\mathrm{SWB}=($ happiness + life satisfaction $) / 2$ & 7.519 & 1.544 & 0.500 & 10.000 \\
\hline Age & 50.782 & 16.425 & 21.000 & 90.000 \\
\hline Gender $(1=$ male $; 2=$ female $)$ & 1.508 & 0.500 & 1.000 & 2.000 \\
\hline Children at home ( 1 yes; 2 no) & 1.591 & 0.492 & 1.000 & 2.000 \\
\hline Education (years) & 12.736 & 4.178 & 0.000 & 30.000 \\
\hline (Daily) activity/work status (4 categories) & 3.050 & 2.653 & 1.000 & 8.000 \\
\hline Religiosity $(0=$ not at all to $10=$ extremely $)$ & 4.622 & 2.903 & 0.000 & 10.000 \\
\hline Social meetings $(1=$ seldom to $3=$ very frequently $)$ & 2.273 & 0.727 & 1.000 & 3.000 \\
\hline Political orientation $(0=$ left to $10=$ right $)$ & 5.133 & 2.090 & 0.000 & 10.000 \\
\hline Trust parliament $(0=$ not at all to $10=$ extremely $)$ & 4.862 & 2.410 & 0.000 & 10.000 \\
\hline Trust legal system $(0=$ not at all to $10=$ extremely $)$ & 5.512 & 2.478 & 0.000 & 10.000 \\
\hline Marital status (4 categories) & 1.914 & 1.241 & 1.000 & 4.000 \\
\hline Self-reported health $(1=\mathrm{v}$. good to $4=$ bad $)$ & 2.127 & 0.825 & 1.000 & 4.000 \\
\hline Cope with finances $(1=$ comfortably to $3=$ with difficulty $)$ & 1.787 & 0.702 & 1.000 & 3.000 \\
\hline
\end{tabular}

interaction as controls in our regressions, comparing the SWB level of each country per round against all others. Furthermore, the data's homogeneity allows models to be generated without missing coefficients in any country-round combinations.

The variables for which responses were provided using a 1-10 Likert scale were treated as continuous. As per Easterbrook et al. (2016, p. 1273), I restricted the (daily)activity/ work status categorical variable to those that were working, unemployed, retired, or stayed home looking after family members. To more easily interpret the resulting coefficients and increase the number of observations in the sub-groups, I also aggregated several other categorical variables. (Frequency of) meeting with friends was reduced from the seven original categories to three. I combined the Bad and Very bad categories of Self-reported Health Status, and the categories Finding it difficult to live on present income and Finding it very difficult to live on present income of coping with finances. I also restricted respondents' age to between 21 and 90 years. The categories of marital status varied between ESS rounds, with three somewhat different definitions used in 2002/2004, 2006/2008, and 2010/2012/2014. I chose to use the categories Married/In civil partnership, Divorced/Separated, Widowed, and Never married/Never in civil partnership. Table 1 presents descriptive statistics of the variables used.

\section{Methods}

\subsection{Fixed effects (OLS) full models}

I initially ran a fixed effects ordinary least squares (OLS) regression with all the aforementioned variables on the right-hand side of the model. I also added the main and interaction effects of the respondent's country and the response round, thereby creating a separate intercept of the dependent variable (SWB) per country per response year (round). 
After running the basic model (Model 1), I calculated outliers using the Cook's distance (Cook 1977). From the initial sample of 155,779 observations, I identified 9200 influential observations. I then reran the same model without these observations $(\mathrm{N}=146,579$ : Model 2). I compared the two models using Akaike's information criteria (AIC) and Schwarz's Bayesian information criteria (BIC) (Akaike 1974; Raftery 1995; Schwarz 1978). Model 2 performed better because the values of both criteria decreased. The explanatory power of Model 2 was 41.6\%, considerably higher than that of Model 1 (34.6\%). The average value of the variance inflation factor (VIF) for both models was smaller than 10 , indicating that there was no serious multicollinearity among their independent variables.

I visually checked how the error terms are distributed in both models by graphing their kernel density and their normal probability plots. As expected, the distribution of the residuals of Model 2 without the outliers is more normally distributed than that of Model 1. The respected graphs are available upon request. The Breusch-Pagan test (Breusch and Pagan 1979) in Model 1 was statistically significant. Thus, to account for potential heteroscedasticity, I ran Model 2 and all subsequent models calculating robust standard errors. In those same models, I also applied population weights based on the relevant ESS documentation (https://www.europeansocialsurvey.org/docs/methodology). Based on Model 2, and to compare the strength of association of each predictor with SWB, I also generated standardised (beta) coefficients. These are measured in standard deviations; thus, their magnitudes can be compared (Table 2).

\subsection{Multilevel (mixed effects) full model}

The two fixed effects OLS models indicated the magnitude and significance of the relationships between SWB and the predictors. To test robustness, I analysed the data with another regression method. With individual-level observations per country and per round, one can describe the potential association between predictors and the dependent variable using multilevel analysis. The chosen dataset is hierarchically nested, with individual responses recorded per round (year) and per country. With seven rounds of ESS data, multilevel analysis accounts for the time series feature of the responses. I used the statistical package Stata version 15.2. For multilevel models, Stata includes the mixed command that generates a fixed and a random part (see Rabe-Hesketh and Skrondal 2012).

Because the dependent variable SWB is in ordinal and discrete form, Wooldridge (2002) suggests that a rank-ordered probit model is most suitable for the analysis. Similarly, Alesina et al. (2004) claim that, when studying happiness, this technique is preferred to OLS estimation (cited in Aassve et al. 2012, p. 76). However, other studies have shown that, in such analyses, there are few differences in the sign and statistical significance of the generated coefficients (Boarini et al. 2012; Ferrer-i-Carbonell and Frijters 2004). Boarini et al. (2012, p. 17) uses OLS regressions since 'the interpretation is more straightforward'. I ran a probit model with the same dependent and independent variables. Confirming prior findings, the sign and statistical significance of each predictor's coefficient were very similar to those of the OLS models. Hence, I did not further pursue ordered probit estimation.

As the dependent variable, I again used the above-described composite version of SWB. As independent variables, I used the same 13 individual-level predictors: age (and age squared), gender, children at home, educational level, work status, religious activity, political orientation, trust towards the parliament, trust towards the legal system, meeting with friends, marital status, self-reported health status, and coping with finances. These comprised the fixed part of the model. In the random part, I defined the respondent's Country as 
Table 2 Individual-level effects on subjective well-being

\begin{tabular}{|c|c|c|c|c|}
\hline Models & 1 & 2 & 2 & 3 \\
\hline \multirow[t]{2}{*}{ Predictor variables } & Full OLS model & OLS w/o outliers & OLS w/o outliers & Mixed w/o outliers \\
\hline & Coefficients & Coefficients & Beta coefficients & Fixed part coefficients \\
\hline Age & $-0.038 * * *$ & $-0.039 * * *$ & -0.411 & $-0.039 * * *$ \\
\hline $\mathrm{Age}^{2}$ & $0.0002 * * *$ & $0.0002 * * *$ & 0.438 & $0.0002 * * *$ \\
\hline \multicolumn{5}{|l|}{ Gender } \\
\hline 1 (Male) & (Base) & (Base) & & (Base) \\
\hline 2 (Female) & $0.121 * * *$ & $0.120 * * *$ & 0.039 & $0.121^{* * *}$ \\
\hline \multicolumn{5}{|l|}{ Children at home } \\
\hline 1 (Yes) & (Base) & (Base) & & (Base) \\
\hline $2(\mathrm{No})$ & $-0.060 * * *$ & $-0.055 * * *$ & -0.017 & $-0.055 * * *$ \\
\hline Education (years) & $-0.008 * * *$ & $-0.010 * * *$ & -0.026 & $-0.010 * * *$ \\
\hline
\end{tabular}

(Daily) activity/work status

1 (Paid work)
2 (Unemployed)
3 (Retired)
4 (Housework/attend
others)

Religiosity
Political orientation

Trust parliament

Trust legal system

(Base)
$-0.535 * * *$
$0.128 * * *$
$0.039 * *$

(Base)

$-0.492 * * *$

$-0.070$

$0.139 * * *$

0.038

$0.079 * * *$

0.015

$0.039 * * *$

$0.038 * * *$

0.071

0.045

0.053

$0.042 * * *$

$0.033 * * *$

$0.034 * * *$

0.095

(Base)

$-0.493 * * *$

$0.138 * * *$

$0.079 * * *$

Social meetings

1 (Seldom/never)
2 (Up to once/week)
3 (Up to daily)

(Base)

$0.329 * * *$

(Base)

$0.532 * * *$

$0.294 * * *$

0.094

$0.494 * * *$

0.160

$0.038 * * *$

$0.033 * * *$

$0.034 * * *$

$0.059 * * *$

Marital status

1 Married/civil part-
nership

2 Divorced/separated

3 Widowed

(Base)

(Base)

$-0.471^{* * *} \quad-0.404 * * *$

$-0.076$

$-0.526 * * *$

$-0.084$

4 Never married/civil part

$-0.584 * * *$

$-0.385^{* * * *}$

$-0.102$

(Base)

$0.295 * * *$

$0.494 * * *$

Self-reported health

1 (Very good)
2 (Good)
3 (Fair)
4 (Bad)

Cope with finances

\begin{tabular}{ll}
1 (Comfortably) & (Base) \\
2 (Adequately) & $-0.389 * * *$ \\
3 (With difficulty) & $-1.240 * * *$ \\
Constant & $8.256 * * *$ \\
Country dummies & Yes \\
Round dummies & Yes \\
\hline
\end{tabular}

(Base)

$-0.394 * * *$

$-0.384 * * *$

$-0.817 * * *$

(Base)

$-0.837 * * *$

$-1.571 * * *$

$-0.403 * * *$

$-0.526 * * *$

$-0.384 * * *$

(Base)

-0.378 ***

$-1.232 * * *$

$8.451 * * *$

Yes

Yes
$-0.125$

$-0.228$

$-0.229$

(Base)

$-0.384 * * *$

$-0.817 * * *$

$-1.572 * * *$

(Base)

$-0.123$

$-0.294$

$-0.378 * * *$

$-1.232 * * *$

$8.266^{* * * *}$

In random part (Level 2) In random part (Level 1) 
Table 2 (continued)

\begin{tabular}{lllll}
\hline Models & 1 & 2 & 2 & 3 \\
Predictor variables & Full OLS model & OLS w/o outliers & OLS w/o outliers & Mixed w/o outliers \\
& Coefficients & Coefficients & Beta coefficients & Fixed part coefficients \\
\hline $\begin{array}{l}\text { Country } \times \text { round interac- } \\
\text { tion }\end{array}$ & $* * *$ & $* * *$ & \\
\hline & & & Mixed part coefficients \\
\hline Variances & & & \\
Country (Level 2) & & & $0.121 * * *$ \\
Round (Level 1) & & & $0.027 * * *$ \\
Residual & & & $1.365 * * *$ \\
$\mathrm{~N}$ & & & 146,579 \\
$\mathrm{r}^{2}$ & 155,779 & 146,579 & $457,340.6$ \\
AIC & 0.346 & 0.416 & $457,597.9$ \\
BIC & $557,547.3$ & $461,815.7$ & \\
VIF & $558,881.5$ & $463,141.7$ & \\
Breusch-Pagan test & 6.93 & 6.92 & \\
chi(1) & $16,251.77 * * *$ & & \\
\hline
\end{tabular}

Full models with and without outliers. Dependent variable: SWB

$* p<0.05 ; * * p<0.01 ; * * * p<0.001$

the third-level grouping variable and the response round (year) as the second-level grouping variable. The first-level comprised the individual observations. I thus built a three-level random intercept model (Model 3) in which SWB is controlled by the variables in the fixed part but has different intercepts (mean values) in each country and for each round (year) in the data. In this model, the relationships between SWB and all predictors in the fixed part have the same slope (Table 2). Individual-level coefficients in all three models remained stable regardless of the model specification and the regression method: their magnitude, sign, and statistical significance did not change considerably between models.

Age The relationship between Age and SWB is not linear (Blanchflower and Oswald 2004, 2008, 2009, 2016; Frijters and Beatton 2012; Steptoe et al. 2015). Age and its quadratic term (age-squared) retained their statistical significance and signs in all three models. Since the coefficient was negative for age but positive for age-squared, happiness declines as one ages up to a certain point, after which it starts increasing again. Thus, the relationship was U-shaped (see also Gerdtham and Johannesson 2001; Subramanian et al. 2005). However, since both coefficients were very small, the decline and rise of SWB as one grows older was slow.

Gender Gender was associated with happiness. In all three models, women were happier than men in a statistically significant way. SWB levels were approximately 0.121 units higher for females compared to males. These results are similar to those of previous studies, which also reported females feeling happier than males (Alesina et al. 2004; Helliwell et al. 2015).

Children at home People with children at home were clearly happier than those without. In all three models, the coefficient for respondents without children at home was negative and statistically significant. This finding is consistent with prior findings, with parents 
consistently reporting greater SWB in activities with children than without (for a comprehensive review, see Musick et al. 2016).

Education Additional education reduces SWB, but only very slightly. Previous studies have reported the opposite. For example, Chen (2012), Easterbrook et al. (2016), and Kuppens et al. (2015) have shown that educational level is associated with more happiness and beneficial personal and sociopolitical outcomes. While this result is interesting, it is later cancelled in some instances when I divide the data into smaller groups.

(Daily) activity/work status The coefficients show that working people seem happier than those who do not work (Di Tella and MacCulloch 2006). In their meta-analysis, Paul and Moser (2009) report that several indicators of mental health, such as SWB, were significantly lower among long-term unemployed compare to workers. However, the three models' results also clearly show that those involved in other daily activities, such as attending others at home, or those that are retired reported higher SWB levels than those who work.

Religiosity In prior studies, people with strong religious beliefs have, on average, reported feeling happier than others (Abdel-Khalek 2011; Clark and Lelkes 2005; Lechner and Leopold 2015; Mollidor et al. 2015). This is confirmed in the present analysis: the respective variable's coefficient had a positive sign and was statistically significant in all three models, as shown in Table 2.

Political orientation It has been reported that conservatives are, on average, happier than those with other political affiliations (Bixter 2015; Burton et al. 2015; Di Tella and MacCulloch 2005; Napier and Jost 2008; Onraet et al. 2013; Schlenker et al. 2012). This was confirmed in the present analysis with respect to respondents' political orientation. As subjects moved from left to right on the political scale, they became increasingly happier, since the respective coefficient was positive and statistically significant.

Trust in country's institutions (parliament and legal system) Hudson (2006) found that trust in the national government and in the law each positively impacts well-being. In the three models, two variables are proxies for such constructs: trust towards the parliament and trust towards the legal system. As in Hudson's research, both correlated positively with SWB.

Meeting with friends/relatives Regarding respondents' social behaviour, the more often they met with friends and relatives, the greater their reported happiness. The coefficients of the sub-cohorts of the variable were positive, statistically significant, and increased as the frequency of meetings increased. This findings accords with previous research (Gundelach and Kreiner 2004; Leung et al. 2013).

Marital status Married people have generally been found to be happier than others [see Helliwell et al. (2017, pp. 5-7) for a brief but comprehensive overview]. At the same time, people who are generically happier are more likely to find and attract partners to marry (De Neve et al. 2013) This in turn, denotes possible selection bias and has been addressed elsewhere by using fixed effects regressions. The positive relationship of Marital Status with happiness nonetheless remains (Clark and Georgellis 2013). Furthermore, the extent to which married people are 'happier' depends on the comparator group. Based on this study's aggregation of the marital status categories in the data, married and civilpartnered people report significantly higher SWB levels compared to all other groups. That is, the coefficients of the divorced or separated, the widowed, and those who have never cohabited have a negative sign and are statistically significant when the reference category is married and/or civil-partnered respondents.

Self-reported health status Previous research indicates that sick people are less happy than healthy ones (Deaton 2008; Steptoe et al. 2015). This was also confirmed in the three models' results. All three sub-cohort coefficients had a negative sign, were statistically 
significant, and were getting smaller than the reference group (very good self-reported health status). As expected, respondents who believed their health to be optimal were also the happiest (linearly).

Coping with finances Prior research suggests that an individual's financial stability and wealth positively influence their SWB (e.g. Senik 2014; Stevenson and Wolfers 2013). In the three models, those who reported being financially comfortable were happier than those just able to make ends meet, and even more so compared to those experiencing financial difficulties. As for self-reported health status, the coefficients of the sub-cohorts of coping with finances were statistically significant, had a negative sign, and decreased as difficulties coping with finances became more acute.

Country and round (year) Although this analysis focused on the effects of individual-level variables, the country, round, and their interaction were used as controls in the OLS fixed effects models, while in the mixed effects estimation, country and round were respectively used as third- and second-level grouping variables. Utilising both variables is justified because international comparisons confirm the intuitive hypothesis that people in different countries report varying SWB levels. In the OLS Models 1 and 2, the coefficients of these two variables were statistically significant per country, per round, and for their interaction. Their reported variances were also statistically significant in the mixed effects Model 3. For more on cross-national comparisons see for example Borooah (2006), Diener and Suh (2003) and Jorm and Ryan (2014).

Beta coefficients In Model 2, age, self-reported health status, and coping with finances were the independent variables with the largest absolute beta coefficients ( $10.20 \mathrm{l}$ or more); that is, these predictors had the strongest influence on SWB, thus reaffirming a finding recently reported by Ngamaba (2017).

\subsection{Models and interactions for sub-groups of the population}

The analysis detailed above confirms the previously established, statistically significant associations with SWB for most of the utilised predictors. However, some authors have described a more complex relationship between these determinants and SWB, with potentially unclear underlying directions of causality. For example, Kuppens et al. (2015, p. 1260) mention that formal education level is positively related to health, wellbeing, social attitudes, and interest in politics. Steptoe et al. $(2015$, p. 640) found that SWB and health are closely linked to age, and that the relation between physical heath and SWB is bidirectional. Löckenhoff and Carstensen (2004) claim that physical health, ageing, and well-being are closely related, especially if interpreted through the prism of the socioemotional selectivity theory (Carstensen et al. 1999). Hirschauer et al. (2015, p. 657) point out that high incomes are often correlated with high stress and little time for leisure and family activities, implying that the relation between financial means and SWB depends on other interacting factors. Lechner and Leopold (2015, p. 172) find that, by attending more religious events, one can cushion the initial drop in life satisfaction caused by unemployment, and can better adapt if worklessness persists. Inglehart (2002) analysed 148,991 individual-level observations from the WVS in 65 countries covering 1981-1997. He found clear evidence of an interaction effect of age and gender on SWB. As he explains,

evidence that younger women tend to be happier than men (especially in richer countries) is offset by the evidence that older women tend to be less happy than 
men in these same societies, producing very small overall gender differences. This interaction tends to conceal statistically significant and theoretically interesting gender differences in subjective well-being. (p. 407).

Dolan et al. (2008) find that having children is negatively associated with SWB in specific groups of the population that face greater efforts to raise them, including single mothers. Finally, Layman (1997) reports that political affiliation is correlated with religiosity, which is, in turn, associated with better health (Green and Elliott 2010).

The common message in the aforementioned studies is that, in many cases, socioeconomic determinants associate with SWB not only directly but also through interactions among themselves. This poses significant challenges to correctly statistically modelling such relationships. To account for and test such complexity, I assert that when the data of the whole population is broken down (divided) into smaller sub-groups, such associations (and non-associations) with SWB continue to be valid for only some of the predictors (those for which the association is quite robust). For some other predictors, I hypothesise that the previously found associations change. Through this process, I can also identify sub-groups of the population whose socioeconomic characteristics have similar coefficients to the whole population and other sub-groups, where these coefficients change their statistical significance and sign when SWB is regressed against them. Put differently, I can reveal which sub-groups behave similarly to the whole population and those which behave dissimilarly in relation to SWB.

\subsection{Deciding between the OLS fixed effects and multilevel (mixed) regression models}

To test these hypotheses, I initially compared two models which data for the whole population are used: Model 2 (OLS fixed effects) and Model 3 (mixed effects). The aim was to choose the most suitable model specification and analysis method for the subsequent tests. Based on the AIC and BIC, Model 3 performed slightly better than Model 2. Nonetheless, when using a mixed (random) model, the number of categories in the grouping variable can potentially be problematic. According to Maas and Hox (2005), having fewer than 50 categories leads to biased estimates of the second-level standard errors. Similar results were reported more recently by Bryan and Jenkins (2013). They recommend avoiding hierarchical/random effects models if there are fewer than 25 level groups. The data utilised here were collected from 16 countries over seven survey rounds. In any event, the present study focuses on individual-level effects which came out very similar regardless of method. Hence, I continued the analysis using only the robust OLS fixed effects regression models.

\subsection{Interactions of the socioeconomic characteristics in $\mathbf{4 1}$ models}

Brambor et al. (2006, p. 64) discuss interactions in regression models. Most relevant for present purposes, they state that:

Analysts should include interaction terms whenever they have conditional hypotheses. A conditional hypothesis is simply one in which a relationship between two or more variables depends on the value of one or more other variables. Perhaps the simplest conditional hypothesis is: 
H1: An increase in $\mathrm{X}$ is associated with an increase in $\mathrm{Y}$ when condition $\mathrm{Z}$ is met, but not when condition $\mathrm{Z}$ is absent.

Thus, I divided the data into smaller groups based on the values of the 13 individual-level predictors. For each new regression using only one sub-group's data, I essentially interacted a fixed value of the respective predictor with the rest, always in relation to SWB. For each new sub-group, I ran a fixed effects OLS regression with the same dependent variable and the same predictors as in the full Model 2. Since the total number of groups was large (41), the confidence level of all regressions was set to $99.99 \%(p=0.001)$. This compensated for the increased probability of Type I error in repeatedly calculating coefficient estimates from the same sample. My reasons for dividing the sample into smaller groups, rather than running interactions with all the data, include simplicity, clarity of interpretation, and attempting to avoid potential methodological pitfalls encountered in similar prior studies. In fact Boarini et al. (2012) apply the same breakdown methodology. However, their detailed analysis only includes a small number of sub-groups formulated from the socioeconomic characteristics of individual-level respondents (ibid., p. 26, Table 6; p. 28, Table 7).

Finally, to re-check the robustness of both methods, I also ran the 41 sub-group models applying multilevel regressions, using the exact same specification as for Model 3 with the whole dataset. The coefficients of the individual predictors were very similar to those in the OLS fixed effects models, in terms of sign, magnitude, and statistical significance. The 41 models in this study are listed in Tables 3, 4, and 5. For comparison, the coefficients of the full Model 2 are presented in the second column from the left.

\subsection{How the $\mathbf{4 1}$ groups were created}

For Age, the sample was divided into three groups: 21-30, 31-60, and 61-90 years old. This division contrasts people still studying or beginning their working careers with those who are working and those close to or in retirement. Four groups were created according to educational level: those with basic schooling (9 years or less), those that studied at high school (10-13 years), those with university-level education (14-18 years), and those who studied for more than 18 years. For each of the variables religious activity, political trust, legal trust, and political orientation (all originally measured on a 1-10 Likert scale), the sample was divided into three groups according to their responses: up to 4, from 5 to 7 , and from 8 to 10 . For the remaining categorical independent variables (gender, children at home, (daily) activity/work status, meeting with friends, marital status, self-reported health status, and coping with finances), subgroups were created based on their own classification. Dummy variables of the 16 countries, the seven rounds, and their interaction were included in all models.

\subsection{Interpretation}

The results presented in Tables 3, 4, and 5 are interpreted by examining and comparing the behaviour of each predictor in the sub-group models when matched against its counterpart in the full Model 2. This enables the predictors robust to such sub-sampling to be identified, namely, those that retain their statistical significance and sign in the full Model 2 in all sub-group models. Initial comparison showed that the unemployed were consistently less 
happy than workers, women were always happier than men, SWB increased with greater conservativism in political views. SWB was also found to increase the more the respondent met with friends and relatives, and to be higher for those who were married or in a civil partnership. Finally, SWB increased with greater self-reported health and ability to cope with finances. For the rest of the predictors, the results were mixed. The non-linear statistically significant association between Age and SWB ceased among the older (Model 6), the retirees (Model 17), and the widowed (Model 36).

In the full Model 2, those with children living at home were generally happier. However, the SWB difference disappeared in nine different sub groups, namely, when the respondent: was older (Model 6), was female (Model 8), had little or extensive education (Models 11 and 14), was retired or taking care of others at home (Models 17 and 18), had little social skills (Model 31), was married or in a civil partnership (Model 34), or had been widowed (Model 36). Such results may be attributed to various factors. One is the burden of raising children. For example, additional children, after the first born, do not increase mothers' SWB while they increase fathers' SWB (Aassve et al. 2012, p. 82). The burden of having children at home could also be greater for elders, who may lack sufficient energy to take care of them, and for those already attending others at home. The results for retirees and the widowed might also be indirectly related to age, since they are typically older. Conversely, this contradicts the notion that having someone at home in old age combats loneliness, hence increasing SWB (Singh and Misra 2009). The result for those with little social skills is plausible: those less inclined to spend time with friends might also be reluctant to have children around. The results in the Education Level and Marital Status sub-groups are not easily interpretable. It could be that people with little education generally work in lower-paying professions or are unemployed, resulting in financial difficulties that cause them to regard taking care of children to be an extra burden. For well-educated individuals, it could be that busy work schedules or extensive other activities prevent them deriving additional happiness from the presence of children in their household. Finally, co-habiting with either a spouse or civil partner apparently cancels the happiness of having children. It could be that, compared to those with children at home, the existence of a co-habiting partner is enough to reduce the difference in SWB to non-statistically significant levels.

Interesting results emerge on examining the other predictor variables, especially those used as continuous in our models. Outlier groups seem to behave differently compared to those in the middle of the response distribution. In the full Model 2, Education Level had a small negative association with happiness. As mentioned earlier, this is opposite to prior research findings. However, when dividing the sample into smaller sub-groups, the coefficients for Education Level changed sign and significance for the less-educated (Model 11) and most-educated (Model 14) respondents. That is, those with basic education do not change their SWB levels with an extra year of study. The same seems to be the case for those with at least 19 years of schooling. For those in between-with 10-18 years of education-results were similar to those of the full model. This indicates that the relationship between Education and SWB is non-linear. We can hypothesize why this is so. One reason might have to do with how well one copes with his/her finances which-in turn usually-correlates positively with SWB. Basic skilled workers get general low salaries. Also in many study disciplines those with higher degrees (e.g. $\mathrm{PhD}$ ) do not necessarily earn more money on the margin compared to those with just Master level education. Religiosity was positively related to SWB, overall. On dividing the sample into three sub-groups, a non-linear association with SWB was found. Those reporting little religious activities (0-4) were less happy with a little extra religious activity (Model 19). The coefficient changed sign from negative to positive in the second sub-group (Model 20), and more than tripled in value among 


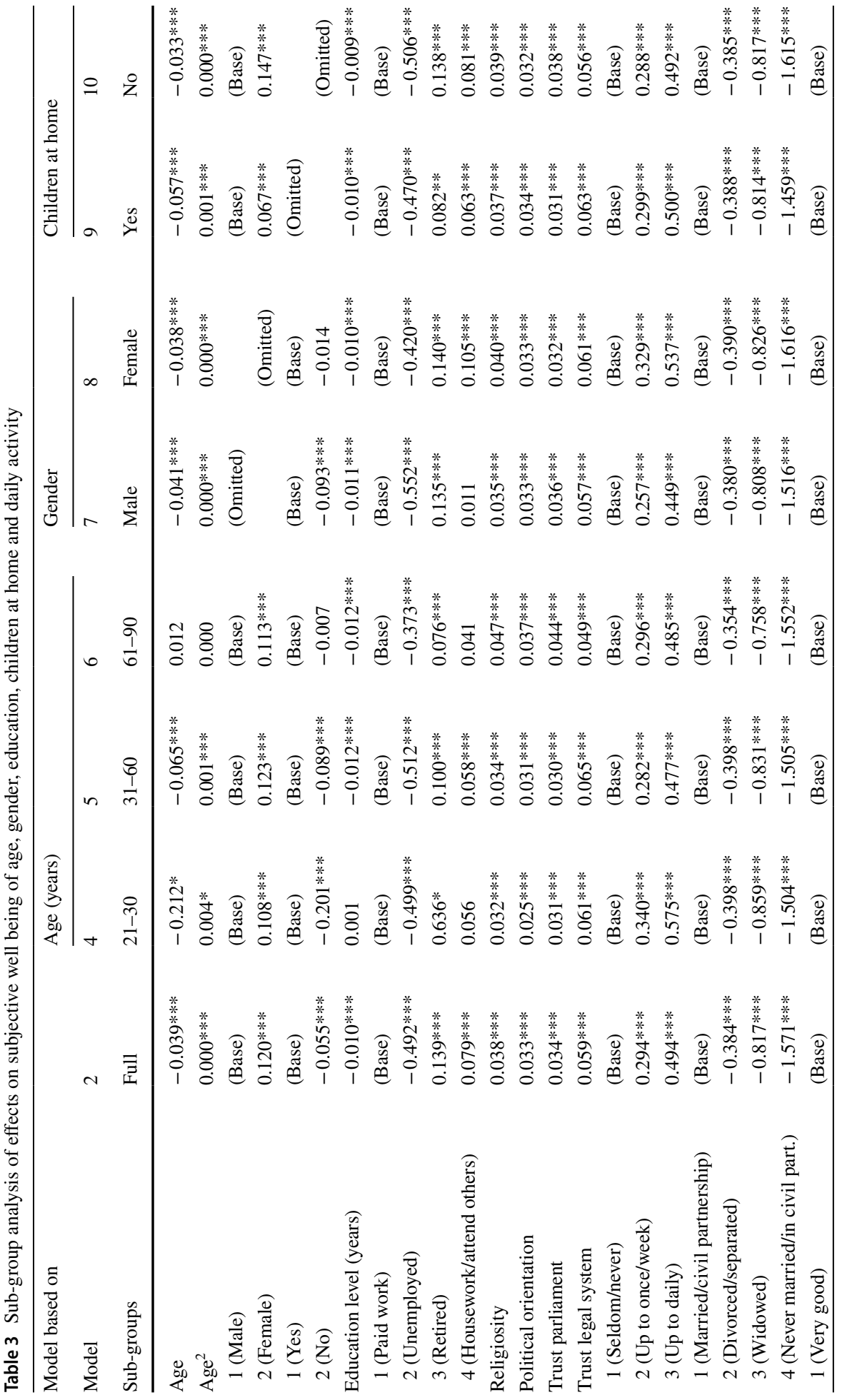




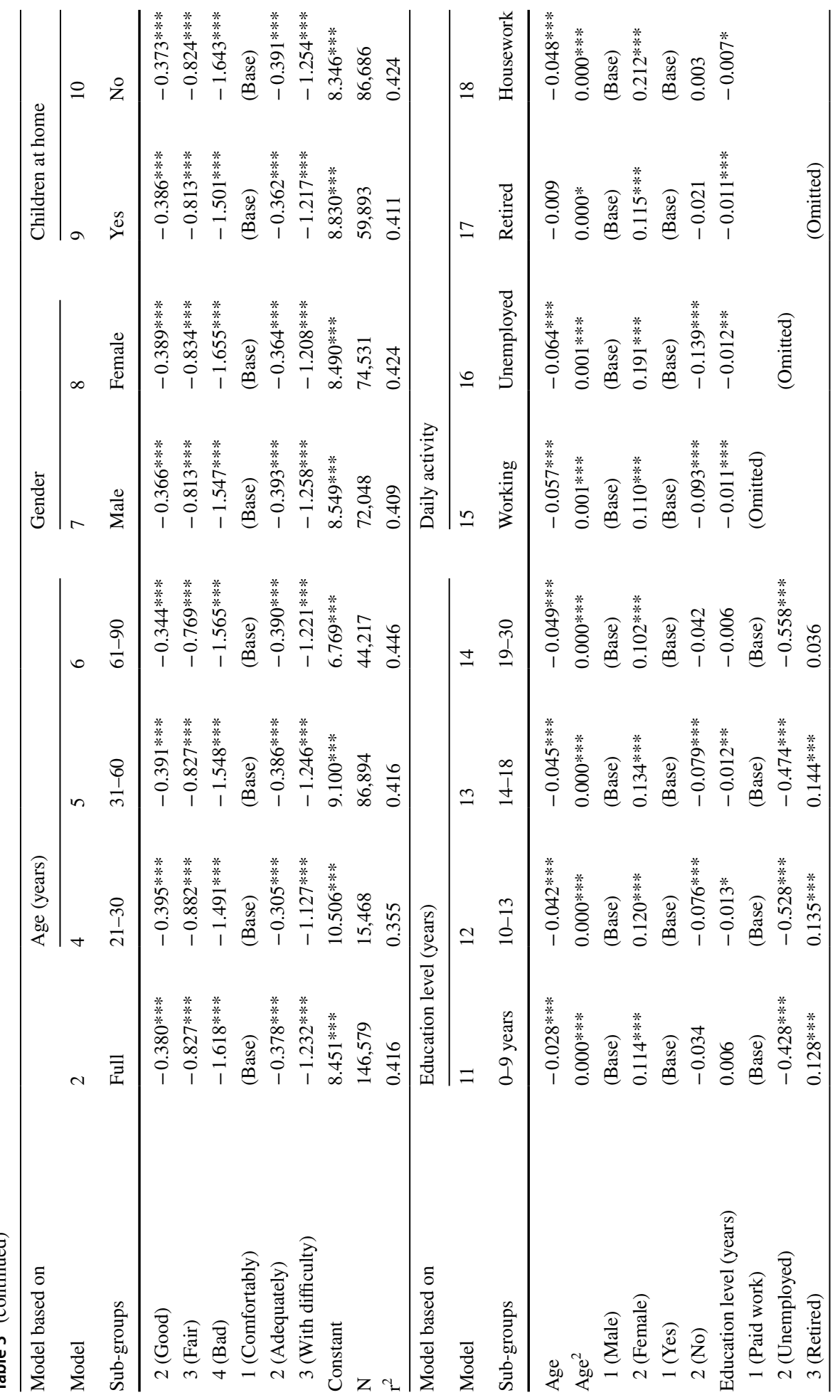




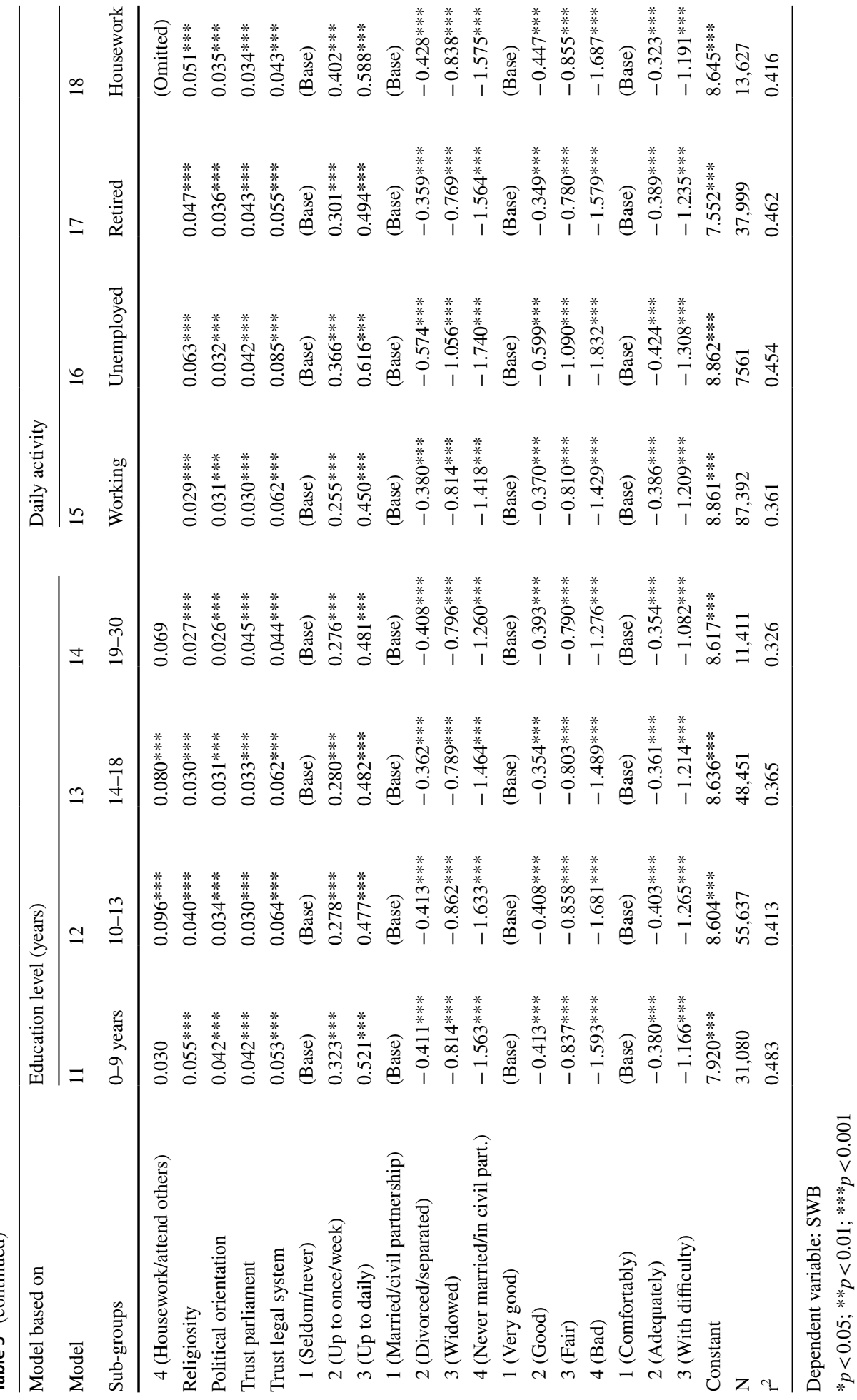




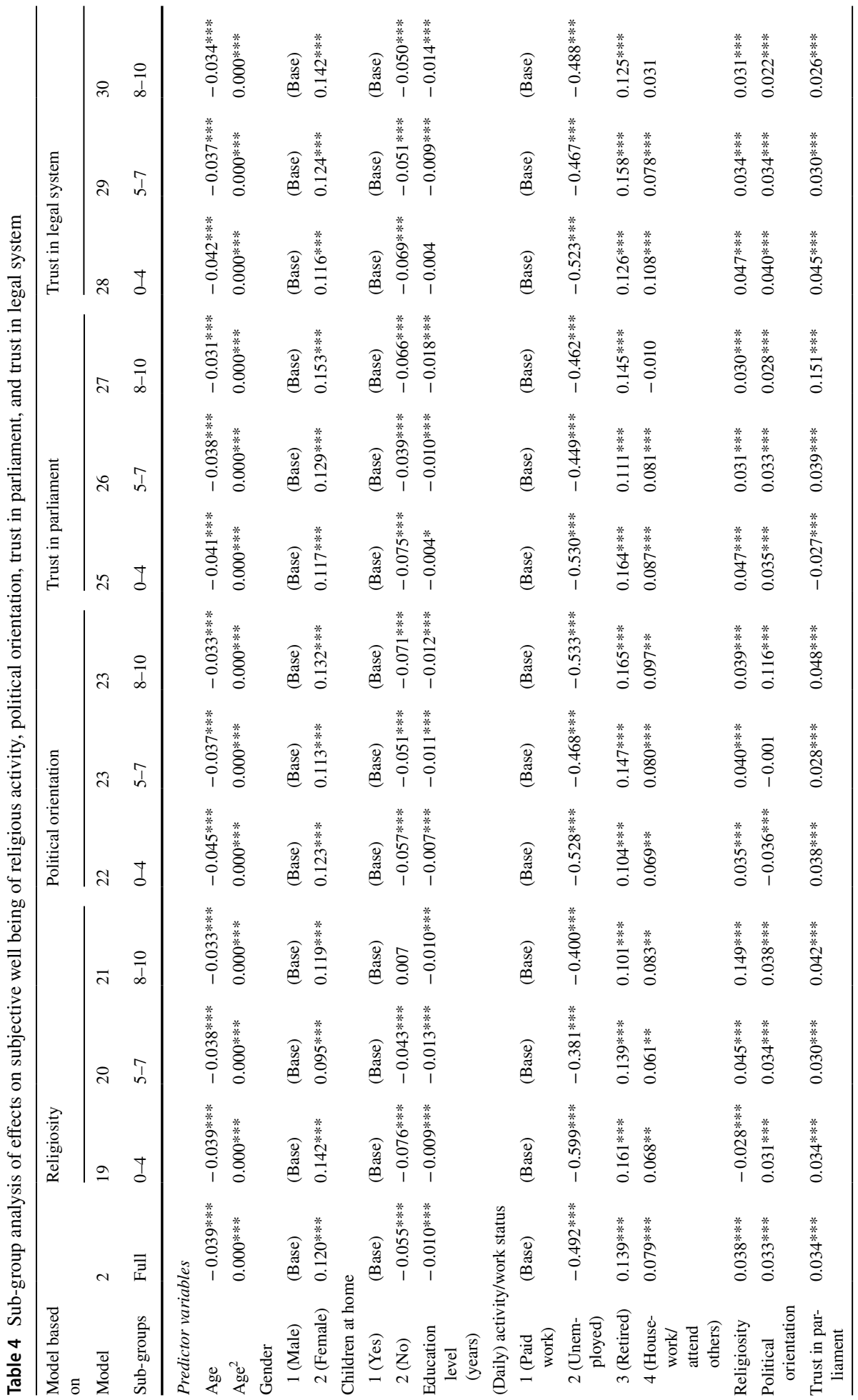




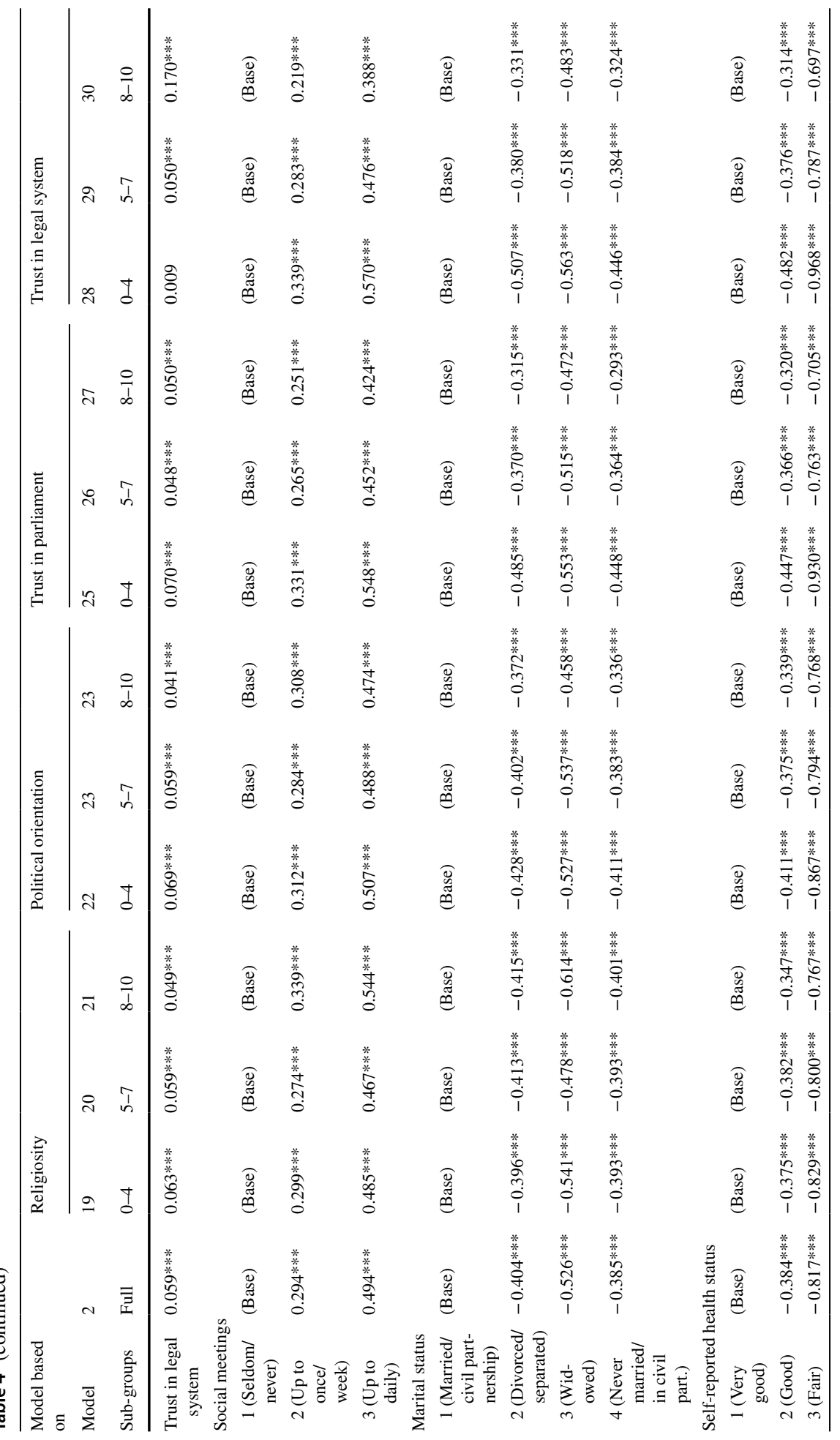




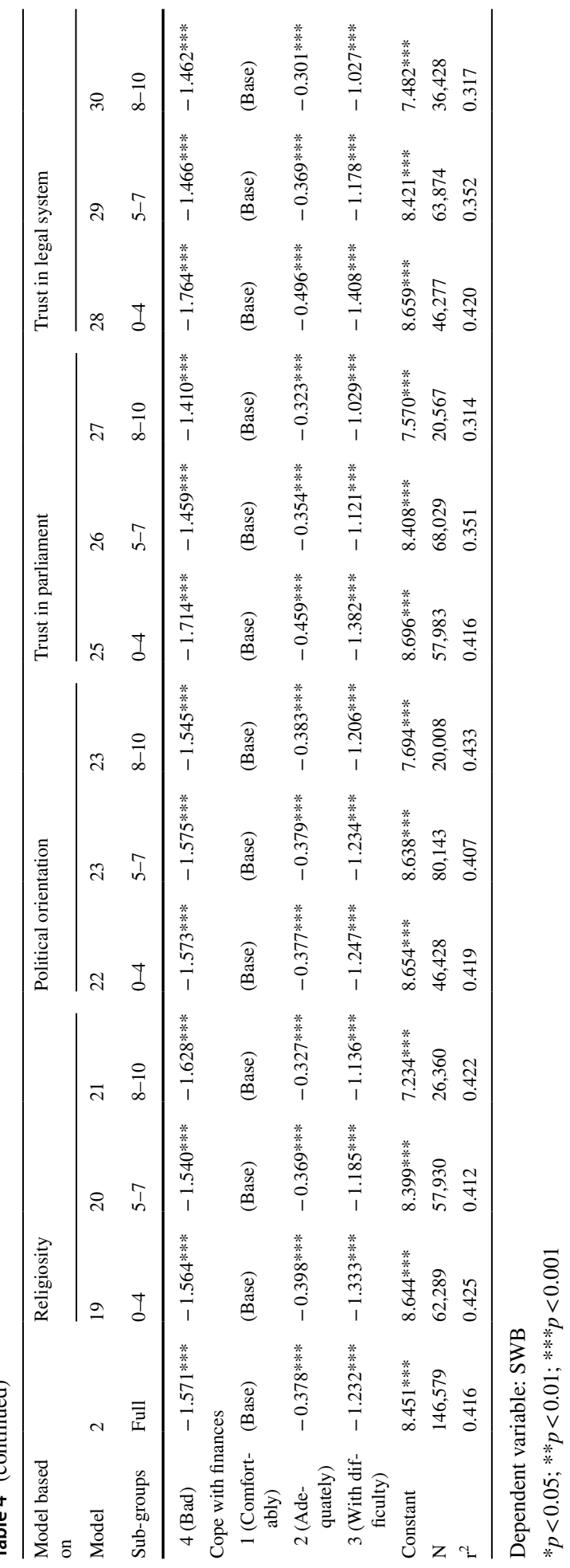




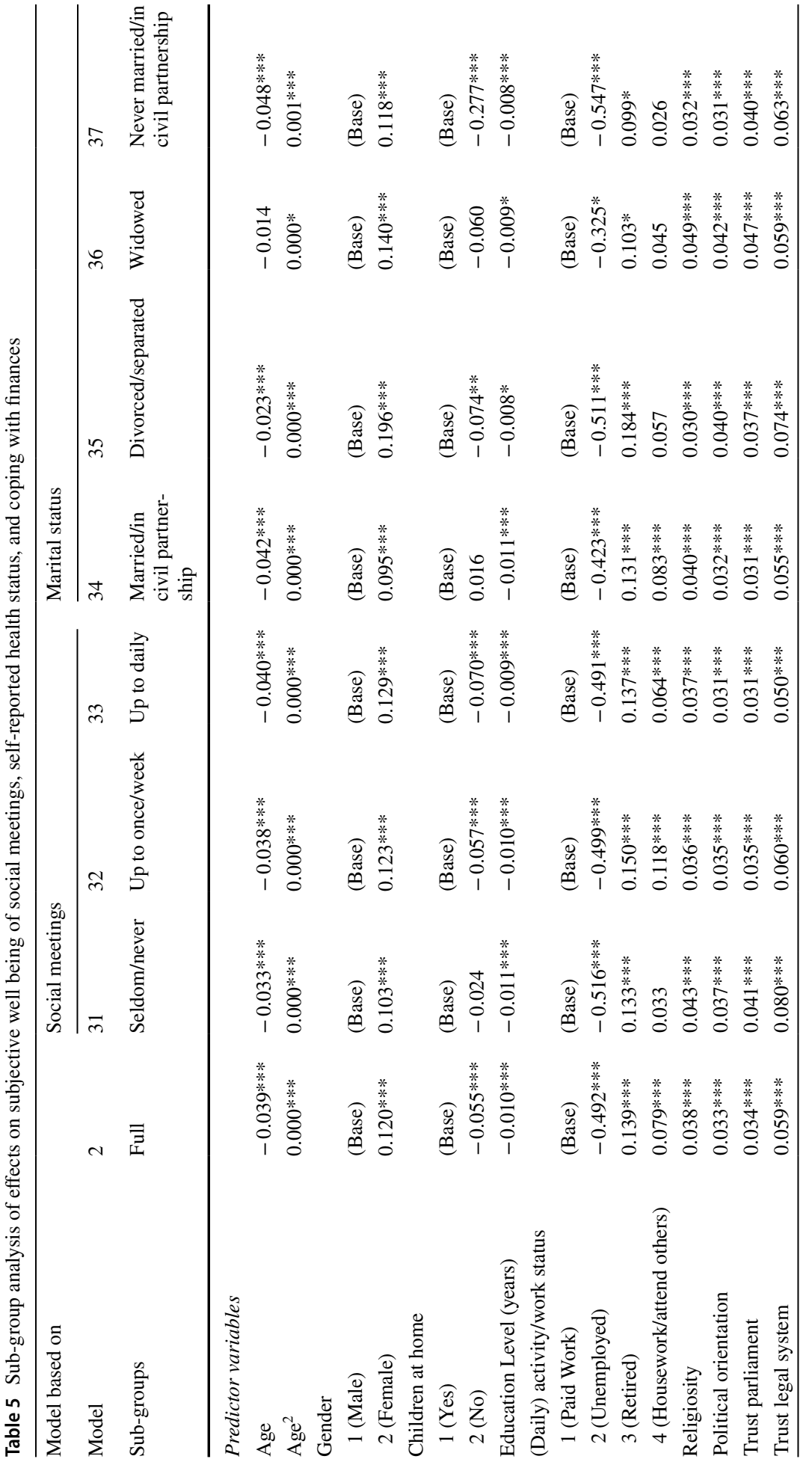




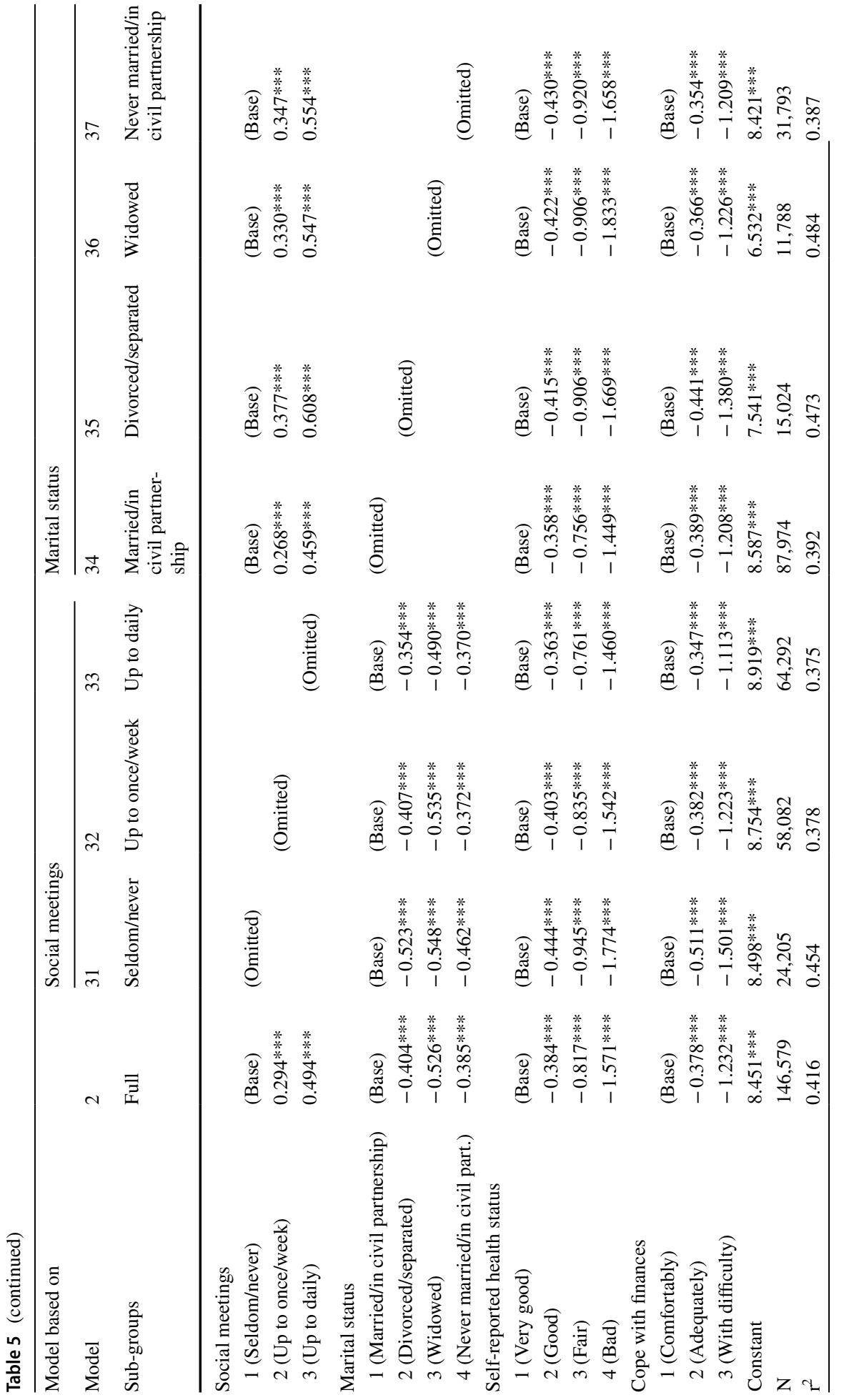




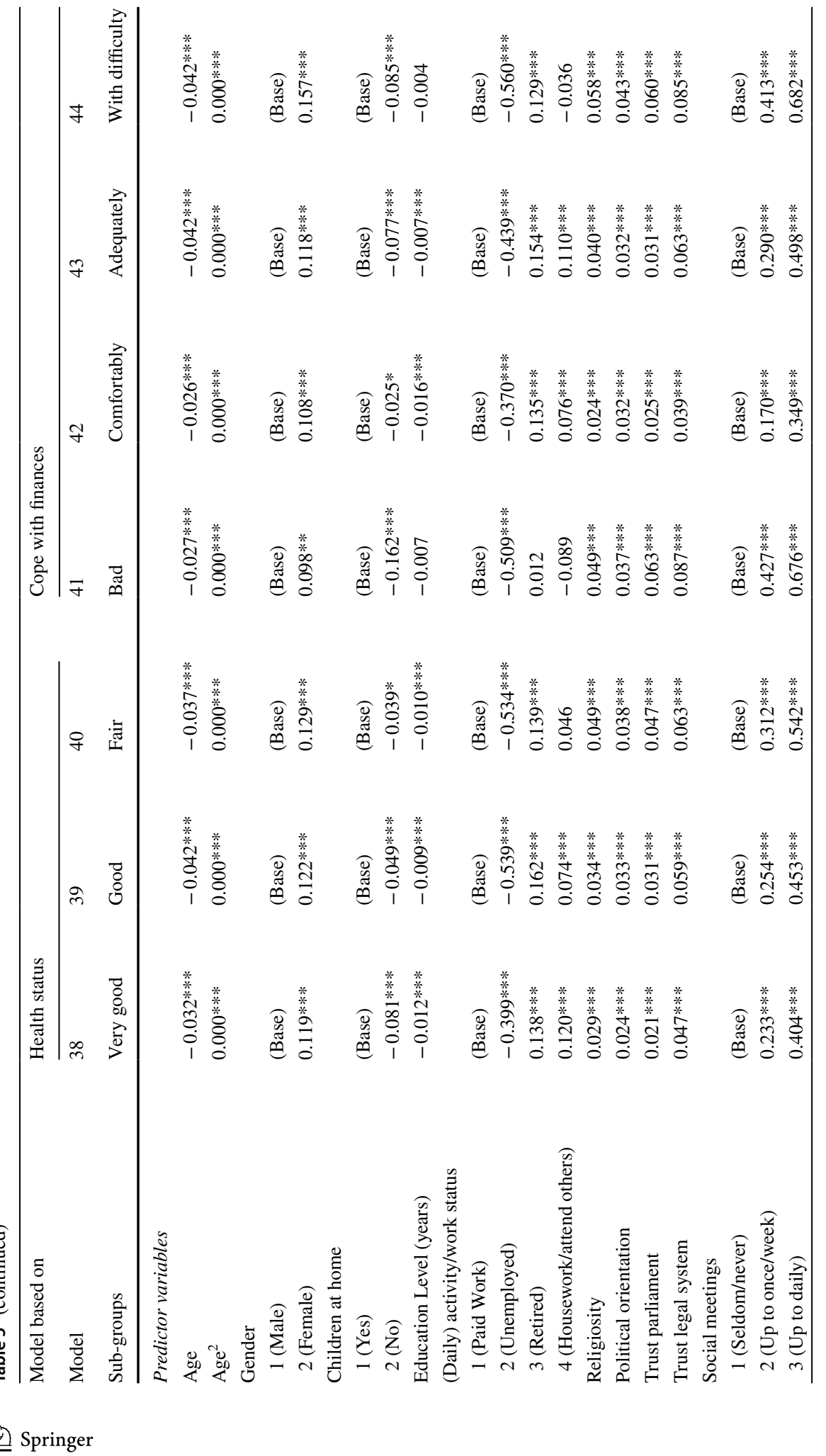




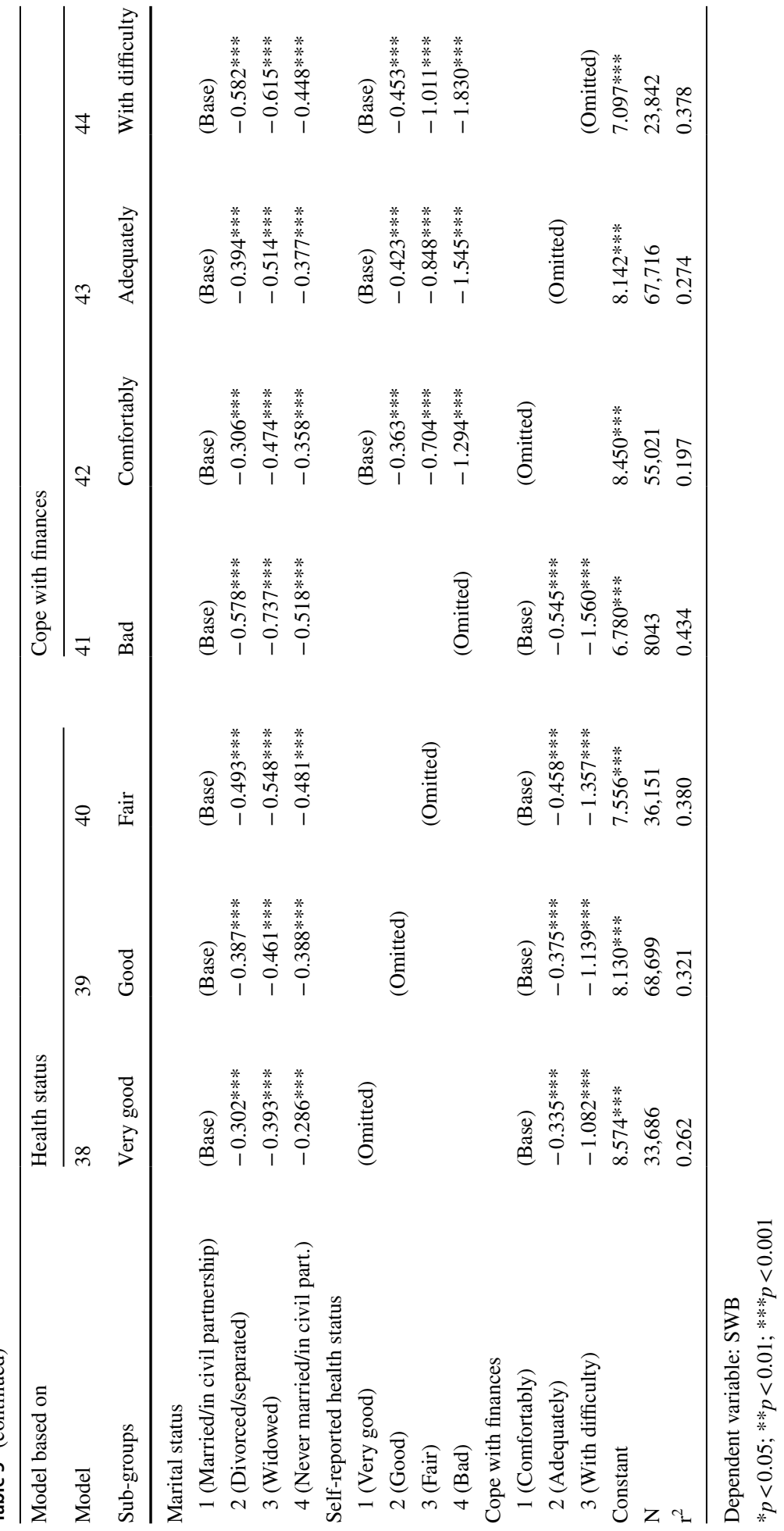


the very religious respondents (Model 21). Why this might be? The obvious answer is that another variable (or variables) affects differently the three groups of Religiosity and their SWB. For example, non-religious people get married less often than religious ones. We also know that those who are married are happier, on average. On the other hand, just being in a civil partnership relationship is also strongly associated with higher SWB. At the same time, people who do not get married are less religious, on average, Hence all evidence indicates contradictory and complex associations. A similar non-linear association was identified for the other three continuous predictors, namely, political orientation, trust in parliament, and trust in the legal system. While positive coefficients were found for the overall sample, groups reporting values from 0 to 4 have negative and statistically significant coefficients (Models 22 and 25) and one positive coefficient which nonetheless is statistically insignificant (Model 28). These relationships change and become strongly positive only in the 8-10 value groups (Models 24, 27, and 30, respectively). Attempting to explain these results I would argue that political orientation is also associated with marital status and coping with finances. Left wing voters are on average less wealthy than conservative ones and are not that religious. Which in turn it could mean that they do not believe in the concept of marriage. Trust in the parliament and in the legal system are again positively associated with political orientation and coping with Finances which as noted earlier, correlate positively with SWB. All in all some of these out-of-norm results could have been caused by higher than just two-way interactions of observable independent variables in our models.

\section{Summary and discussion}

In the present study, I analysed data from 16 countries and seven rounds of the ESS (2002-2014). Since prior research has found significant associations between self-reported SWB and individual-level socioeconomic characteristics, this study's objective was to explore whether these associations persist in different sub-groups of the population. That is, I attempted to identify so-called 'robust' and 'weaker' determinants of SWB. The former group's statistically significant effect on SWB remains intact regardless of the sub-population examined, whereas the latter group's effect changes in several population sub-groups.

The sample was divided into 41 sub-groups, based on separate value ranges for the continuous individual characteristics and on cohorts for other categorical predictors. The logic behind the approach is simple. A complex phenomenon becomes easier to examine and comprehend once you "break" it into smaller, more manageable parts. By dividing the data into smaller groups each of which was similar in a specific characteristic, 1 was able to study the respective group's behavior and compare it against results of other sub-groups as well those of the total sample. For example, if the results came similar to those when analyzing data from the whole sample at hand, 1 concluded that this characteristic of that specific subgroup was not associated with SWB. Conversely, the whatever-differences-found, could be attributed to that one characteristic with more confidence. In statistical jargon this specific characteristic potentially interacted with all other observable factors examined.

When running models for each group and applying the same specification as for the whole sample, I identified robust and weak socioeconomic characteristics with respect to their association with SWB. The robust characteristics comprise work (versus unemployment), female (versus male), political orientation, social interaction with friends, marital status, self-reported health status, and coping with finances. All continued to behave as in 
the full model, and were positively associated with SWB. When it comes to the rest of the individual-level characteristics however, the associations of age, gender, children at home, education, religiosity and trust with SWB disappeared. Such results are opposite to prior theoretical and empirical findings.

Reflecting on why only some individual-level socioeconomic characteristics maintain robust associations with SWB in all 41 population sub-groups, it is apparent that the relation between the SWB and some characteristics is not straightforward. As discussed earlier, there are obvious interactions among them. In some cases, such interactions affect how specific characteristics associate with SWB; in some other cases, they play no role whatsoever.

The nature of the paper is purely descriptive and exploratory. The goal at this stage was to identify characteristics and sub-groups in which previously identified associations with SWB no longer hold. Apart from arguing that the divergences are due to complex interactions, I do not attempt to explain this in a more conceptual way due to space limitations, this will be undertaken in the future.

The study has a few limitations which are linked to the type of the data utilised. Although the sample size was sufficient to study sub-groups each based on one characteristic, it was not possible to combine several characteristics in sub-groups. Therefore, more complicated simultaneous interactions were not studied. The existence of such complexity is evident from careful examination of Tables 3, 4, and 5. For example, the statistical significance of Education Level ceases in the models of sub-groups whose respondents report bad health (Model 41) or poor coping with finances (Model 44). This indicates that interactions likely exist among more than two determinants of SWB. In addition, some might argue that examining data from 16 only countries, and using the multivariate method of analysis with fixed-effects OLS regressions, restricts inferences from the results to the population at hand. Finally, the study uses cross-sectional time series data, since the individuals surveyed are not the same in each ESS round. Responses from the same individuals (a panel) might yield somewhat different results. For example, Ferrer-i-Carbonell and Frijters (2004) report that the income effect on life satisfaction falls by as much as one third when controlling for individual-level fixed effects, compared to other estimation methods. It is, thus, more informative and accurate to measure SWB levels of the same respondents over time. Ferrer-i-Carbonell and Frijters (2004) also contend that the effect of unemployment on happiness is more accurately estimated when examining individuals' happiness changes when they lose their job, rather than comparing happiness reports of unemployed and employed individuals (cited in Ferrer-i-Carbonell 2013, p. 60). The value of panel data in such research is also emphasised in Dolan et al.'s (2008) comprehensive review of economic literature. They assert that, without panel data, the direction of causality of certain determinants of SWB is sometimes unclear.

To conclude, this paper's principal contribution is that some of its results contradict those of previous studies. It is evident that indirect associations and interdependencies exist among the examined socioeconomic characteristics with respect to SWB. In this respect, this research is exploratory in nature. More analysis is warranted in the future to further scrutinise and then conceptually explain the detailed interactions of SBW predictors. One possible approach is to use different datasets, apply the same methodology - that is, use the same predictors and dependent variable, and divide the data into similar subgroups-and then compare the results. Similar kinds of comparisons have been conducted, for example, by Easterbrook et al. (2016) where they analysed data from the British Social Attitude Survey (BSAS), the British Household Panel Survey (BHPS) and the International Social Survey Program (ISSP). 
I would also argue that such exploratory analysis is useful, especially for policy design and implementation. Empirical research on how socioeconomic characteristics are related to SWB has previously been considered in specific public interventions concerning unemployment and health. As Hirschauer et al. (2015, p. 671) discuss:

The manner in which evidence from happiness research is to be used towards enlightening policy makers in their quest to find adequate policies, cannot be determined in general but depends largely on the respective policy field and problem under consideration.

The identification of robust and weak determinants of SWB in special sub-groups of the general population is, of course, not the only criterion based on which such policies are designed. Nonetheless, when such programmes concerning those most-in-need are implemented, such identifications have a complementary role and can give valuable feedback in enhancing efficiency and effectiveness.

Acknowledgements Open access funding provided by University of Turku (UTU) including Turku University Central Hospital.

Open Access This article is distributed under the terms of the Creative Commons Attribution 4.0 International License (http://creativecommons.org/licenses/by/4.0/), which permits unrestricted use, distribution, and reproduction in any medium, provided you give appropriate credit to the original author(s) and the source, provide a link to the Creative Commons license, and indicate if changes were made.

\section{References}

Aassve, A., Goisis, A., Sironi, M.: Happiness and childbearing across Europe. Soc. Indic. Res. 108(1), 65-86 (2012)

Abdel-Khalek, A.M.: Subjective well-being and religiosity in Egyptian college students. Psychol. Rep. 108(1), 54-58 (2011)

Akaike, H.: A new look at the statistical model identification. IEEE Trans. Autom. Control 19(6), 716-723 (1974)

Alesina, A., Di Tella, R., MacCulloch, R.: Inequality and happiness: Are Europeans and Americans different? J. Public Econ. 8(9), 2009-2042 (2004)

Bixter, M.T.: Happiness, political orientation, and religiosity. Personal. Individ. Differ. 72, 7-11 (2015)

Blanchflower, D.G., Oswald, A.J.: Money, sex and happiness: an empirical study. Scand. J. Econ. 106(3), 393-415 (2004)

Blanchflower, D.G., Oswald, A.J.: Is well-being U-shaped over the life cycle? Soc. Sci. Med. 66(8), 17331749 (2008)

Blanchflower, D.G., Oswald, A.J.: The U-shape without controls: a response to Glenn. Soc. Sci. Med. 69(4), 486-488 (2009)

Blanchflower, D.G., Oswald, A.J.: Antidepressants and age: a new form of evidence for U-shaped wellbeing through life. J. Econ. Behav. Organ. 127, 46-58 (2016)

Boarini, R., Comola, M., Smith, C., Manchin, R., de Keulenaer, F.: What Makes for a Better Life? The Determinants of Subjective Well-Being in OECD Countries-Evidence from the Gallup World Poll. OECD Statistics Working Papers, 2012/03. OECD Publishing, Paris (2012). https://doi. org/10.1787/5k9b9ltjm937-en

Borooah, V.K.: How much happiness is there in the world? A cross-country study. Appl. Econ. Lett. 13(8), 483-488 (2006)

Brambor, T., Clark, W.R., Golder, M.: Understanding interaction models: improving empirical analyses. Polit. Anal. 14(1), 63-82 (2006). https://doi.org/10.1093/pan/mpi014

Breusch, T.S., Pagan, A.R.: A simple test for heteroscedasticity and random coefficient variation. Econom. J. Econom. Soc. 47, 1287-1294 (1979) 
Broyd, A., Jolley, S., Johns, L.: Determinants of subjective well-being in people with psychosis referred for psychological therapy in South London. Br. J. Clin. Psychol. 55, 429-440 (2016). https://doi. org/10.1111/bjc. 12112

Bryan, M.L., Jenkins, S.P.: Regression Analysis of Country Effects Using Multilevel Data: A Cautionary Tale (ISER Working Paper No. 2013-14, August). Institute for Social and Economic Research, University of Essex (2013)

Burton, C.M., Plaks, J.E., Peterson, J.B.: Why do conservatives report being happier than liberals? The contribution of neuroticism. J. Soc. Polit. Psychol. 3(1), 89-102 (2015)

Carstensen, L.L., Isaacowitz, D.M., Charles, S.T.: Taking time seriously: a theory of socioemotional selectivity. Am. Psychol. 54(3), 165-181 (1999)

Chen, W.: How education enhances happiness: comparison of mediating factors in four East Asian countries. Soc. Indic. Res. 10(1), 117-131 (2012)

Cheng, H., Furnham, A.: The associations between parental socio-economic conditions, childhood intelligence, adult personality traits, social status and mental well-being. Soc. Indic. Res. 117(2), 653-664 (2014)

Clark, A.E., Georgellis, Y.: Back to baseline in Britain: adaptation in the British household panel survey. Economica 80(319), 496-512 (2013)

Clark, A.E., Lelkes, O.: Deliver Us from Evil: Religion as Insurance (PSE Working Papers No. 2005-43) (2005)

Cole, K., Daly, A., Mak, A.: Good for the soul: the relationship between work, wellbeing and psychological capital. J. Socio-Econ. 38, 464-474 (2009). https://doi.org/10.1016/j.socec.2008.10.004

Cook, R.D.: Detection of influential observation in linear regression. Technometrics 19(1), 15-18 (1977)

De Neve, J.-E., Diener, E., Tay, L., Xuereb, C.: The objective benefits of subjective well-being. In: Helliwell, J., Layard, R., Sachs, J. (eds.) World Happiness Report 2013. UN Sustainable Development Solutions Network, New York (2013)

Deaton, A.: Income, health, and well-being around the world: evidence from the Gallup World Poll. J. Econ. Perspect. 22(2), 53-72 (2008)

DeNeve, K.M., Cooper, H.: The happy personality: a meta-analysis of 137 personality traits and subjective well-being. Psychol. Bull. 124(2), 197-229 (1998)

Di Tella, R., MacCulloch, R.: Partisan social happiness. Rev. Econ. Stud. 72(2), 367-393 (2005)

Di Tella, R., MacCulloch, R.: Some uses of happiness data in economics. J. Econ. Perspect. 20(1), 25-46 (2006)

Diego-Rossell, P., Tortora, R., Bird, J.: International determinants of subjective well-being: living in a subjectively material world. J. Happiness Stud. 1(1), 123-143 (2018). https://doi.org/10.1007/s1090 2-016-9812-3

Diener, E.: Subjective well-being. Psychol. Bull. 95, 542-575 (1984)

Diener, E., Biswas-Diener, R.: Happiness: Unlocking the Mysteries of Psychological Wealth. Blackwell Publishing, Malden (2008)

Diener, E., Chan, M.Y.: Happy people live longer: subjective well-being contributes to health and longevity. Appl. Psychol. Health Well-Being 3(1), 1-43 (2011). https://doi.org/10.1111/j.1758-0854.2010.01045.x

Diener, E., Ryan, K.: Subjective well-being: a general overview. S. Afr. J. Psychol. 39(4), 391-406 (2009)

Diener, E., Suh, E.M.: National differences in subjective wellbeing. In: Kahneman, D., Diener, E., Schwarz, N. (eds.) Well-Being: The Foundations of Hedonic Psychology, pp. 434-450. Russell Sage Foundation, New York (2003)

Dolan, P., Peasgood, T., White, M.: Do we really know what makes us happy? A review of the economic literature on the factors associated with subjective well-being. J. Econ. Psychol. 29, 94-122 (2008)

Easterbrook, M.J., Kuppens, T., Manstead, A.S.: The education effect: higher educational qualifications are robustly associated with beneficial personal and socio-political outcomes. Soc. Indic. Res. 126(3), 1261-1298 (2016)

Eger, R.J., Maridal, J.H.: A statistical meta-analysis of the wellbeing literature. Int. J. Wellbeing 5(2), 45-74 (2015)

Ferrer-i-Carbonell, A.: Happiness economics. SERIEs 4(1), 35-60 (2013). https://doi.org/10.1007/s1320 9-012-0086-7

Ferrer-i-Carbonell, A., Frijters, P.: How important is methodology for the estimates of the determinants of happiness? Econ. J. 114, 641-659 (2004)

Fleche, S., Smith, C., Sorsa, P.: Exploring Determinants of Subjective Wellbeing in OECD Countries: Evidence from the World Value Survey (OECD Economics Department Working Paper No. 921). OECD Publishing, Paris (2011). https://doi.org/10.1787/5kg0k6zlcm5k-en

Frijters, P., Beatton, T.: The mystery of the U-shaped relationship between happiness and age. J. Econ. Behav. Organ. 82(2), 525-542 (2012) 
Gerdtham, U.-G., Johannesson, M.: The relationship between happiness, health, and socio-economic factors: results based on Swedish microdata. J. Socio-Econ. 30(6), 553-557 (2001)

Green, M., Elliott, M.: Religion, health, and psychological well-being. J. Relig. Health 49(2), 149-163 (2010)

Gundelach, P., Kreiner, S.: Happiness and life satisfaction in advanced European countries. Cross Cult. Res. 38(4), 359-386 (2004)

Headey, B., Wearing, A.: Subjective well-being and coping with adversity. Soc. Indic. Res. 22, 327-349 (1990). https://doi.org/10.1007/BF00303830

Headey, B., Wearing, A.J.: Understanding Happiness: A Theory of Subjective Well-Being. Longman Cheshire, Melbourne (1992)

Helliwell, J.F., Barrington-Leigh, C.P.: Measuring and Understanding Subjective Well-Being (NBER Working Paper No. 15887) (2010)

Helliwell, J.F., Layard, R., Sachs, J.: World Happiness Report 2013. Sustainable Development Solutions Network, New York (2015)

Helliwell, J.F., Layard, R., Sachs, J. (eds.): World Happiness Report 2016, Update, vol. I. Sustainable Development Solutions Network, New York (2016)

Helliwell, J.F., Aknin, L.B., Shiplett, H., Wang, S.: Social Capital and Prosocial Behavior as Sources of Well-Being (NBER Working Paper No. 23761) (2017)

Hirschauer, N., Lehberger, M., Musshoff, O.: Happiness and utility in economic thought—or: What can we learn from happiness research for public policy analysis and public policy making? Soc. Indic. Res. 121(3), 647-674 (2015)

Hudson, J.: Institutional trust and subjective well-being across the EU. Kyklos 59(1), 43-62 (2006)

Inglehart, R.: Gender, aging, and subjective well-being. Int. J. Comp. Sociol. 43(3-5), 391-408 (2002)

Jorm, A.F., Ryan, S.M.: Cross-national and historical differences in subjective well-being. Int. J. Epidemiol. 43, 330-340 (2014)

Jun, K.-H.: Re-exploration of subjective well-being determinants: full-model approach with extended crosscontextual analysis. Int. J. Wellbeing 5(4), 17-59 (2015). https://doi.org/10.5502/ijw.v5i4.405

Kilian, R., Lauber, C., Kalkan, R., Wulf, D., Roessler, W., Wiersma, D., et al.: The relationships between employment, clinical status, and psychiatric hospitalisation in patients with schizophrenia receiving either IPS or a conventional vocational rehabilitation programme. Soc. Psychiatry Psychiatr. Epidemiol. 47, 1381-1389 (2012). https://doi.org/10.1007/s00127-011-0451-Z

Kuppens, T., Easterbrook, M.J., Spears, R., Manstead, A.S.: Life at both ends of the ladder. Education-based identification and its association with well-being and social attitudes. Personal. Soc. Psychol. Bull. 41(9), 1260-1275 (2015)

Lane, T.: How does happiness relate to economic behaviour? A review of the literature. J. Behav. Exp. Econ. 68, 62-78 (2017)

Layman, G.C.: Religion and political behavior in the United States: the impact of beliefs, affiliations, and commitment from 1980 to 1994. Public Opin. Q. 61(2), 288-316 (1997)

Lechner, C.M., Leopold, T.: Religious attendance buffers the impact of unemployment on life satisfaction: longitudinal evidence from Germany. J. Sci. Study Relig. 54(1), 166-174 (2015)

Leung, A., Kier, C., Fung, T., Fung, L., Sproule, R.: Searching for happiness: the importance of social capital. In: Delle Fave, A. (ed.) The Exploration of Happiness: Present and Future Perspectives, pp. 247267. Springer, Dordrecht (2013)

Löckenhoff, C.E., Carstensen, L.L.: Socioemotional selectivity theory, aging, and health: the increasingly delicate balance between regulating emotions and making tough choices. J. Personal. 72(6), 13951424 (2004)

Lukaschek, K., Anushiya, V., Johar, H., Weiland, N., Ladwig, K.-H.: "In the mood for ageing": determinants of subjective well-being in older men and women of the population-based KORA-Age study. BMC Geriatr. 17, 126 (2017). https://doi.org/10.1186/s12877-017-0513-5

Lyubomirsky, S., King, L., Diener, E.: The benefits of frequent positive affect: Does happiness lead to success? Psychol. Bull. 131, 803-855 (2005)

Maas, C.J.M., Hox, J.J.: Sufficient sample sizes for multilevel modeling. Methodology 1(1), 86-92 (2005)

McCrae, R.R., Costa Jr., P.T.: Validation of the five-factor model of personality across instruments and observers. J. Personal. Soc. Psychol. 52(1), 81-90 (1987)

McCrae, R.R., Costa Jr., P.T.: Personality trait structure as a human universal. Am. Psychol. 52(5), 509-516 (1997)

McCrae, R.R., Terracciano, A.: Universal features of personality traits from the observer's perspective: data from 50 cultures. J. Personal. Soc. Psychol. 88(3), 547-556 (2005)

Mollidor, C., Hancock, N., Pepper, M.: Volunteering, religiosity and well-being: interrelationships among Australian churchgoers. Ment. Health Relig. Cult. 18(1), 20-32 (2015) 
Musick, K., Meier, A., Flood, S.: How parents fare: mothers' and fathers' subjective well-being in time with children. Am. Sociol. Rev. 81(5), 1069-1095 (2016)

Napier, J.L., Jost, J.T.: Why are conservatives happier than liberals? Psychol. Sci. 19(6), 565-572 (2008)

Ngamaba, K.H.: Determinants of subjective well-being in representative samples of nations. Eur. J. Public Health 27(2), 377-382 (2017). https://doi.org/10.1093/eurpub/ckw103

Onraet, E., Van Hiel, A., Dhont, K.: The relationship between right-wing ideological attitudes and psychological well-being. Personal. Soc. Psychol. Bull. 39(4), 509-522 (2013)

Paul, K.I., Moser, K.: Unemployment impairs mental health meta-analyses. J. Vocat. Behav. 74(3), 264-282 (2009)

Rabe-Hesketh, S., Skrondal, A.: Multilevel and Longitudinal Modeling Using Stata, 3rd edn. Stata Press, College Station (2012)

Raftery, A.E.: Bayesian model selection in social research. Sociol. Methodol. 25, 111-163 (1995)

Schlenker, B.R., Chambers, J.R., Le, B.M.: Conservatives are happier than liberals, but why? Political ideology, personality, and life satisfaction. J. Res. Personal. 46(2), 127-146 (2012)

Schwarz, G.: Estimating the dimension of a model. Ann. Stat. 62(2), 461-464 (1978)

Senik, C.: Wealth and happiness. Oxf. Rev. Econ. Policy 30(1), 92-108 (2014)

Singh, A., Misra, N.: Loneliness, depression and sociability in old age. Ind. Psychiatry J. 18(1), 51-55 (2009)

Steptoe, A., Deaton, A., Stone, A.A.: Subjective wellbeing, health, and ageing. Lancet 385(9968), 640-648 (2015)

Stevenson, B., Wolfers, J.: Subjective well-being and income: Is there any evidence of satiation? Am. Econ. Rev. 103(3), 598-604 (2013)

Stiglitz, J.E., Sen, A., Fitoussi, J.-P.: Report by the Commission on the Measurement of Economic Performance and Social Progress. INSEE, Paris (2009)

Stiglitz, J.E., Sen, A., Fitoussi, J.-P.: MIS-Measuring Our Lives: Why GDP Doesn't Add Up: The Report of the Commission on the Measurement of Economic Performance and Social Progress. The New Press, New York (2010)

Subramanian, S.V., Kim, D., Kawachi, I.: Covariation in the socioeconomic determinants of self-rated health and happiness: a multivariate multilevel analysis of individuals and communities in the USA. J. Epidemiol. Community Health 59(8), 664-669 (2005)

Sumner, L.W.: Welfare, Happiness, and Ethics. Clarendon Press, Oxford (1996)

Tay, L., Diener, E.: Needs and subjective well-being around the world. J. Personal. Soc. Psychol. 101, 354365 (2011). https://doi.org/10.1037/a0023779

Taylor, D.: Wellbeing and welfare: a psychosocial analysis of being well and doing well enough. J. Soc. Policy 40(4), 777-794 (2011)

Wooldridge, J.M.: Econometric Analysis of Cross Section and Panel Data. MIT Press, Cambridge (2002)

Publisher's Note Springer Nature remains neutral with regard to jurisdictional claims in published maps and institutional affiliations. 